\title{
LXVIII. The induction-coil
}

\section{E. Taylor Jones D.Sc. \& D.E. Roberts B.Sc.}

To cite this article: E. Taylor Jones D.Sc. \& D.E. Roberts B.Sc. (1911) LXVIII. The induction-coil , Philosophical Magazine Series 6, 22:131, 706-720, DOI: 10.1080/14786441108637168

To link to this article: http://dx.doi.org/10.1080/14786441108637168

册 Published online: 20 Apr 2009.

Submit your article to this journal $\pi$

Џlll Article views: 3

Q View related articles ¿

Citing articles: 1 View citing articles $\square$ 
a large reservoir, and observing the quantity of inert gas which had accumulated after a series of suitable intervals of time, it would in all probability be possible to deduce from an examination of the results, not only the final equilibrinm amount of helium and neon together, but also the quantities of the two individually, as well as their coefficients of diffusion.

Palmer Physical Laboratory, Princeton, N.J.

LXVIII. The Induction-Coil. By E. Taylor Jones, D.Sc., Professor of Physics in the University College of North Wales, Bangor, and D. E. RoBents, B.Sc., Fellow of the University of Wales*.

[Plates XII. \& XIII.]

THE experiments described in the present paper were 1 made with the object of determining the elements (periods, amplitudes, damping-factors, and phases) of the two electrical oscillations which are set up in the secondary of an induction-coil when the primary current is interrupted, and of calculating hence the maximum value of the secondary potential and the potential at any time during the oscillations.

The principal difficulties connected with the calculation of the secondary potential of an induction-coil are (1) the determination of the effective self- and mutual-inductances of the coils, (2) the determination of the capacity of the secondary coil ; the first owing to the want of proportionality between magnetic induction and magnetizing force in the iron core, the second owing to the smallness of the capacity and to the fact that the capacity is distributed along the coil. Some attempt was made in the experiments described below to overcome these difficulties, but there are other circumstances, including condenser losses, hysteresis, and irregularities in the working of the interrupter, which will have to be taken into account, or avoided, before a complete solution of the induction-coil problem can be reached.

The papers of Oberbeck + , Walter $\ddagger$, and Lord Rayleigh $\S$, on induction-coil potentials are well-known and are therefore only mentioned here.

* Communicated by the Authors:

† Oberbeck, Wied. Ann., lxii. p. 109 (1897); lxiv. p. 193 (1898).

\pm Walter, Wied. Ann., lxii. p. 300 (1897); lxvi. p. 623 (1898).

$\$$ Rayleigh, Płil. Matg., ii. p. 581 (1001). 
General Description of the Method.

In a former communication one of us ${ }^{*}$ arrived at the following expression for the difference of potential at the terminals of the secondary of an induction-coil at any time $t$ seconds after a current $i_{0}$ is interrupted in the primary:-

$$
\begin{aligned}
2 \mathrm{~V}_{2} & =\frac{\mathrm{M} i_{0} \mathrm{~T}}{\left(\mathrm{~T}^{2}-\mathrm{T}^{2}\right) \cos \delta} e^{-\frac{t}{\mathrm{~T}^{2}}\left(\frac{\theta_{1}+\theta_{2}}{2}-\beta\right)} \sin \left(\frac{t}{\mathrm{~T}}-\delta\right) \\
& -\frac{\mathrm{M} i_{0} \mathrm{~T}^{\prime}}{\left(\mathrm{T}^{2}-\mathrm{T}^{2}\right) \cos \delta^{\prime}} e^{-\frac{t}{\mathrm{~T}^{2}}\left(\frac{\theta_{1}+\theta_{2}}{2}+\beta\right)} \sin \left(\frac{t}{\mathrm{~T}^{\prime}}-\delta^{\prime}\right), . .
\end{aligned}
$$

where $M$ is the mutual inductance of the primary and secondary coils,

$$
\theta_{1}=\frac{1}{2} \mathrm{R}_{1} \mathrm{C}_{1}, \quad \theta_{2}=\frac{1}{2} \mathrm{R}_{2} \mathrm{C}_{2}
$$

$1 / 2 \pi \mathrm{T}$ and $1 / 2 \pi \mathrm{T}^{\prime}$ are the frequencies of the two oscillations culculated from the well-known expression for coupled circuits

$$
\left.8 \pi^{2} n^{2}=\frac{1}{1-k^{2}}\left[\frac{1}{\mathrm{~L}_{1} \mathrm{C}_{1}}+\frac{1}{\mathrm{~L}_{z} \mathrm{C}_{Q}} \pm \sqrt{ }\left(\frac{1}{\mathrm{~L}_{1} \mathrm{C}_{1}}-\frac{1}{\mathrm{~L}_{2} \mathrm{C}_{2}}\right)^{2}+\frac{4 k^{2}}{\mathrm{~L}_{1} \mathrm{C}_{1} \mathrm{~L}_{2} \mathrm{C}_{2}}\right\}\right]
$$

$k$ being the coupling coefficient $\mathrm{M} / \sqrt{\mathrm{L}_{1} \mathrm{~L}_{2}}$.

The quantity $\beta$, and the phase-angles $\delta, \delta^{\prime}$, are to bo calculated from the constants of the circuits as described in the former paper above referred to. $R_{1}, R_{2}, C_{1}, C_{2}, L_{1}, L_{2}$ are the primary and secondary resistances, capacities, and selfinductances.

In the paper referred to the above expression (1) was worked out for an air-core induction-coil with various condensers in the primary and secondary circuits, and the curve of secondary potential plotted from the results. The curve was also obtained photographically in each case by means of an electrostatic oscillograph, and was found to agree closely in its general form with the curve calculated from (1). The differences were mainly in the damping factors, and these discrepances probakly arose from losses in the primary condensers.

Strictly speaking, the expression (1) is not applicable to a coil with an iron core, owing to the variable permeability of iron; all that can be expected is that suitable mean values

* E. T. Jones, Phil. Mag. January 1909, p. 28. This expression for the secondary potential was obtained by an application of Lrude's 'Theory of the Oscillation Transformer,'Ann. der Physik, xiii. p. 512, 1904: 
of the inductances may be found which will serve for the evaluation of the periods and amplitudes during at least a portion of the time of discharge. This was borne in mind in the experiments described below, and it was intended as far as possible to determine the mean inductances corresponding to the early portion of the discharge, since this portion includes the maximum secondary potential which is the quantity of greatest importance in an induction-coil.

The inductances of the primary and secondary coils were determined by electrical oscillation methods; a condenser of known capacity being connected to the primary (or secondary) coil, and the curve of secondary potential being photographed and measured by methods which have been described in detail in former papers *.

It was thought that by measuring that portion of the damped oscillation-curve in which the current amplitude was approximately the same as in the early part of the doubleperiod discharge, appropriate mean values of the inductances would be obtained, since the iron core passed through the same series of magnetic states in both cases. It was searcely to be expected that this plan would lead to very accurate results, but it was hoped that it would suffice for the purposes of an approximate estimation of the secondary potential.

The coupling coefficient of the two coils was determined by finding the period of the oscillations of the secondary circuit, connected to a condenser, with the primary open and closed. The ratio of the squares of these periods is then $\left(1-k^{2}\right)$.

The value of the expression (1) was worked out for two induction-coils, a 12-inch spark coil by Max Kohl, and an 18-inch coil by the same maker. In the experiments with the smaller coil a condenser was connected to the terminals of the secondary coil ; otherwise the secondary capacity would have been so small that one of the oscillations would be too rapid to be accurately recorded by the oscillograph. In the case of the larger coil it was unnecessary to connect a condenser to the secondary, but the primary capacity was larger than is generally employed with induction-coils.

In these experiments the electrostatic oscillograph was provided with a steel strip under great tension in order to bring the amplitudes of the curves down to moderate dimensions. The metallic parts of the instrument were well sheathed in ebonite, and the terminals well separated, in order to prevent sparking.

* E. T. Jones, loc. cit. pp. 33-35; and Mhil. Mag. A ugust 1007. 
The interrupter consisted of a copper rod making contact with the interior of an iron vessel containing petrolenm. The rod was raised automatically, as the reflected rays of light were crossing the photographic plate, by a lever placed beneath the rotating mirror.

\section{Experiments with a Condenser in the Secondary Circuit.}

When a condenser is connected to the terminals of the secondary, the capacity of the secondary coil only comes in as a small correction, and it is unnecessary to know its value very accurately. It consists partly of the internal capacity, depending upon the capacity of one section of the coil on the next and upon the number of sections, and partly of the external capacity which depends upon the position of the coil with respect to other bodies and especially with respect to the primary coil. The methods by which these capacities were determined were described in a previous communication *.

Case I.-In the first experiment with the smaller induction-coil the primary was drawn out of the secondary until the curve of secondary potential, as shown by the oscillograph, had a simple and well-marked form, corresponding probably to some simple ratio between the two frequencies of oscillation. This case was intended as a preliminary test of the method.

The photograph is shown in Plate XII. fig. 8. The current broken in the primary circuit was 5.05 amperes, and the ordinate of the curve represents the square of the secondary potential at any subsequent time. The curve was photographed for four different values of the primary current $i_{0}$ ranging from $2 \cdot 8$ to 5.05 amperes, and the general form of the curve was the same in all, only the amplitude varying with the current. The amplitude of the first wave in each was measured on the negative with a travelling microscope and the values found were, within 4 per cent., proportional to the squares of the primary currents.

The lower curve in the photographs represents the oscillations of a 768 tuning-fork photographed simultaneously. Immediately after these curves were obtained another curve was photographed showing the secondary potential for an air-core induction-coil with known capacities and inductances in its circuits. This curve was similar to one of those discussed in the previous paper above referred to, and to which the expression (1) may be assumed to apply. By

* E. T. Jones, Phil. Mag., A ugust 1907, p. 248. 


\section{Prof. E. Taylor Jones and Mr. D. E. Roberts on}

both measuring and calculating the maximum amplitude in this curve the electrometer may therefore be standardised.

The iron-cored induction coil was again connected to the oscillograph and photographs obtained for the purpose of measuring the primary and secondary inductances, the coupling coefficient, and the capacities if these were not already known. The values of these constants in the present case were as follows :-

$$
\begin{aligned}
& \mathrm{L}_{1}=\cdot 02342 \text { henries. } \\
& \mathrm{L}_{2}=258 \cdot 3 \quad, \\
& \mathrm{M}=1 \cdot 811 \quad, \\
& k^{2}=0.5424 \\
& \mathrm{C}_{1}=15.95 \text { microfarads. } \\
& \mathrm{C}_{2}=0.0004748,
\end{aligned}
$$

This value of $\mathrm{C}_{2}$ includes the capacity of the electrometer and of the secondury coil. The resistances of the primary and secondary coils were 0.32 and 14000 ohms.

The two frequencies of oscillation, calculated by (2), were

$$
n_{1}=237 \cdot 4, \quad n_{2}=737 \cdot 0,
$$

and the expression (1) for the secondary potential, taking the primary current $i_{0}$ as 5.05 amperes, becomes in volts

$$
\begin{aligned}
2 \mathrm{~V}_{2} & =15230 e^{-6 t} \sin (86453 t-0.55) \\
& -4910 e^{-68 \cdot 15 t} \sin (266334 t-1 \cdot 72),
\end{aligned}
$$

in which $t$ is the time in seconds after the interruption of the primary current, and the angles are given in degrees. 'This was worked out for a number of values of $t$, the results squared and plotted in a curve the early portion of which is shown in fig. 1 .

Fig. 1.

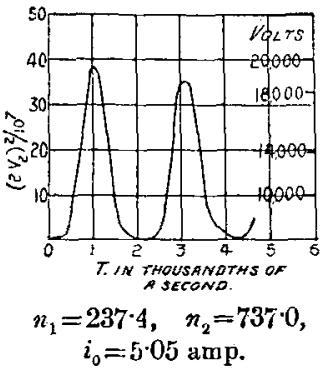

Fig. 2.

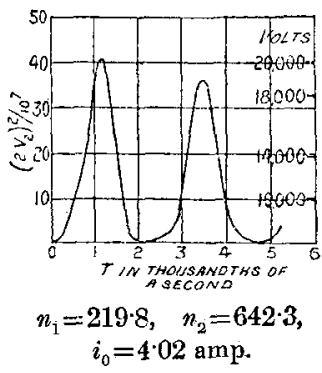

The agreement between this curve and the photograph in 
Plate XII. fig. 8, is evidently sufficiently close to justify the application of the method to the present case. The damping of the waves is much greater in the photograph than in the calculated curve. This is also the case in the other experiments described below, and is to be expected since the only cause of damping taken into account in the calculation is that which arises from the resistances of the circuits.

The calculated maximum value of the secondary potential is 19650 volts, and the amplitude of the first wave in the photograph is $0.9276 \mathrm{~cm}$. Now the standardising curve obtained with the air-core coil showed that a deflexion of $0.3032 \mathrm{~cm}$. in the photograph corresponds to 10200 volts. Hence taling the deflexion as proportional to the square of the potential, the amplitude of the first wave represents a maximum potential of 17850 volts.

When it is remembered that the damping due to hysteresis and condenser losses have been entirely neglected, the agreement between the culculated and observed values of the maximum secondary potential is perhaps as close as could be expected.

Case 11.-This case is similar to the first except that the primary coil with its iron core was placed further inside the secondary in order to increase the secondary self-inductance and the coupling coefficient. The secondary capacity (a variable condenser with paraffin-oil dielectric) was adjusted so as to give a form of oscillograph curve slightly different from that of Case I. The constants of the circuits were :-

$$
\begin{aligned}
& \mathrm{L}_{1}=\cdot 02331 \text { henries. } \\
& \mathrm{L}_{2}=428 \cdot 1 \quad, \\
& \mathrm{M}=2 \cdot 436 \quad " \\
& k^{2}=0.5949 \\
& \mathrm{C}_{1}=15 \cdot 95 \text { microfarads. } \\
& \mathrm{C}_{2}=0.000499, \\
& \mathrm{R}_{1}, \mathrm{R}_{2} \text { as before. }
\end{aligned}
$$

The frequencies, calculated by (2), were

$$
n_{1}=219 \cdot 8, \quad n_{2}=642 \cdot 3,
$$

and, with $i_{0}=4.02$ amperes, the expression for the secondary potential in volts is

$$
\begin{aligned}
2 \mathrm{~V}_{2} & =15320 e^{-5 \cdot 46 t} \sin (79146 t-0 \cdot 51) \\
& -5247 e^{-51 \cdot 85 t} \sin (231221 t-1 \cdot 49) .
\end{aligned}
$$




\section{Prof. E. Taylor Jones and Mr. D. E. Roberts on}

The curve representing the square of this expression is shown in fig. 2, the corresponding photograph in Plate XII. fig. 9, and again there is close agreement in the form of the curve.

The maximum secondary potential (calculated) is 20085 volts, the observed value (by comparison with the curve given by the air-core coil) 17250 volts.

Case III.-The primary coil was placed fully inside the secondary so as to give the maximum values of the secondary self-inductance and the coupling coefficient. Owing to sparking between the plates of the oil condenser this was replaced by a leyden-jar. The constants for this case were :-

$$
\begin{aligned}
& \mathrm{L}_{1}=\cdot 02303 \text { benries. } \\
& \mathrm{L}_{2}=513 \quad " \\
& \mathrm{M}=3 \cdot 197 \quad " \\
& k^{2}=0 \cdot 8643 \\
& \mathrm{C}_{1}=15 \cdot 95 \text { microfarads. } \\
& \mathrm{C}_{2}=\cdot 001051 \quad " \\
& \mathrm{R}_{1}, \mathrm{R}_{2} \text { as before. }
\end{aligned}
$$

The ratis of the frequencies was considerably greater than in the previous cases, their values being

$$
n_{1}=170 \cdot 1, \quad n_{2}=908 \cdot 8 .
$$

With a primary current of 8.5 amperes the expression for the secondary potential is

$$
\begin{aligned}
2 V_{2} & =30090 e^{-6 \cdot 217 t} \sin (61232 t-0.55) \\
& -56 \pm 0 e^{-145 \cdot 6 t} \sin (327157 t-2 \cdot 9) .
\end{aligned}
$$

The curve representing the square of this expression is given in fig. 3 , and the corresponding photograph in Plate XII. fig. 10. Though there are differences in detail, in general form the resemblance between the two curves is close, and there is also good agreement, in this as well as in all the other cases, between the calculated and observed values of $t$ at which the potential is zero. The calculated value of the maximum secondary potential is 31730 , the observed value 26500 volts.

The greatest spark-length observed in this case between two brass spheres, each 2 centimetres in diameter, was 8.5 millimetres. 
Fig. 3.

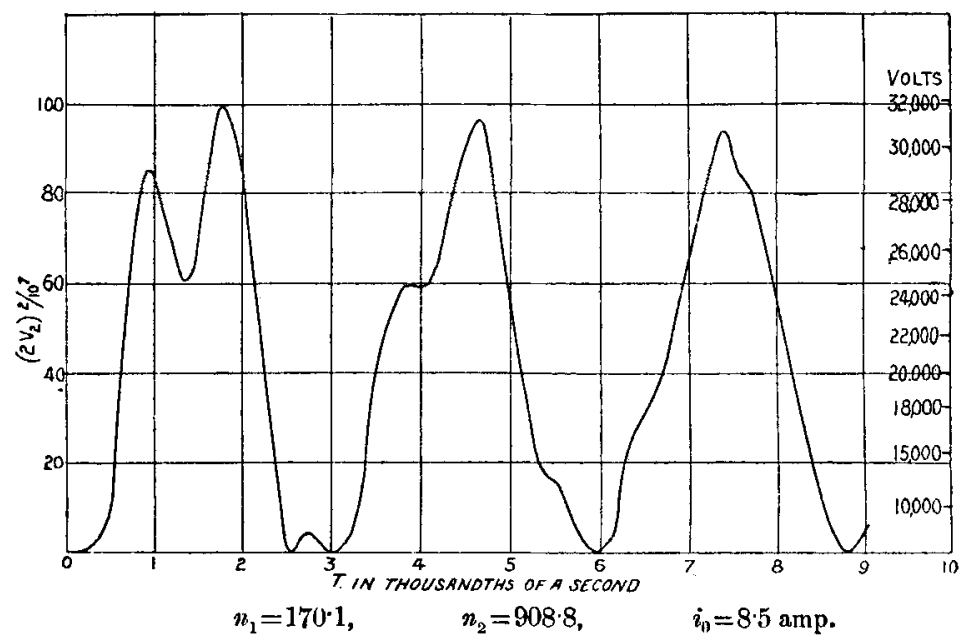

Case IV.-This differs from the last only in the use of a smaller capacity in the secondary circuit, its value being $\cdot 0002213$ microfarad. The frequencies were

$$
n_{1}=230 \cdot 2, \quad n_{2}=1444 \cdot 7,
$$

and with $i_{0}=6.75$ amperes the secondary potential is given by

$$
\begin{aligned}
2 \mathrm{~V}_{2} & =32411 e^{-4 \cdot 884 t} \sin (82888 t-0 \cdot 29) \\
& -5168 e^{-145 \cdot 6 t} \sin (520086 t-1 \cdot 82) .
\end{aligned}
$$

The maximum value of this expression, which occurs at the second peak of the curve, is 36060 volts. The curvo is shown in fig. 4 (p. 714).

Several photographs were taken for this case, and though similar in their general features they differed considerably from one another in detail. Sometimes the first peak was equal to or higher than the second, sometimes the peak in the second principal wave was higher than both maxima in the first. These differences arise apparently from irregularities in the working of the interrupter, which seem to alfect chiefly the amplitude and phase of the more rapid oscillation. The photograph in Plate XII. fig. 11 shows the type which occurred most frequently. By comparison with the air-core coil the highest point of the curve was found to correspond to a secondary (observed) potential of 27560 volts. 
714 Prof. E. Taylor Jones and Mr. D. E. Roberts on

The greatest sparking-distance between the two spheres under the circumstances of this experiment was found to be 1. centimetre.

Fig. 4.

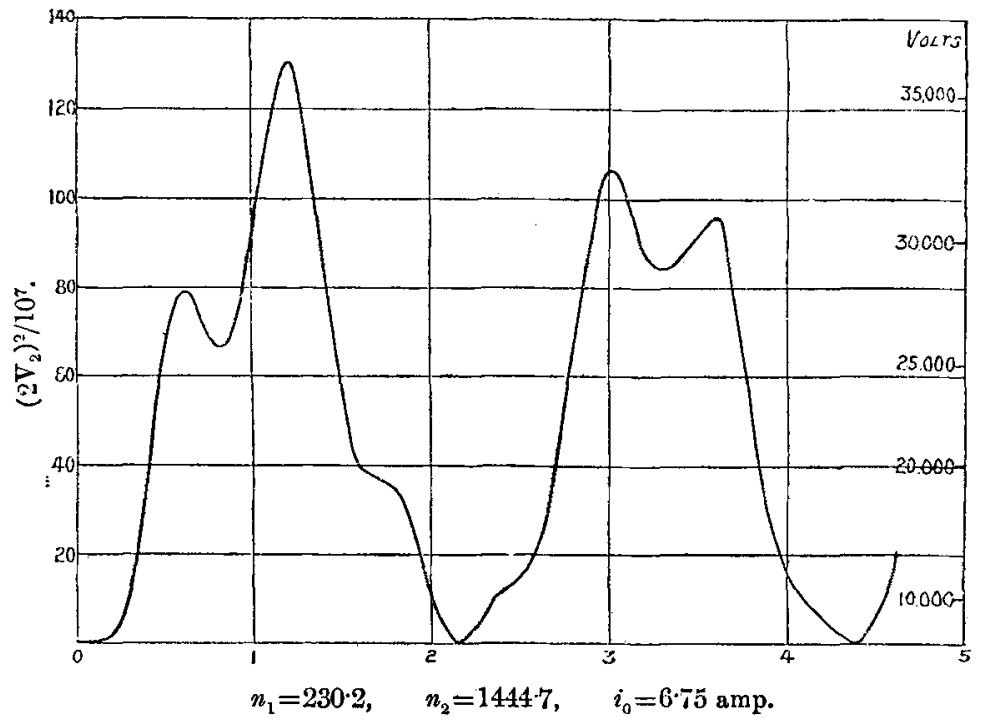

It will be observed that in all the above cases the calculated value of the secondary potential is considerably greater than the observed value, and that the percentage difference increases with the potential.

\section{Experiments with no Condenser in the Secondary Circuit.}

If the condenser is removed from the secondary circuit of the smaller induction-coil, one of the oscillations becomes too rapid to be faithfully recorded by the oscillograph. The 18-inch spark coil was therefore used for the three following cases, its secondary having much greater self-inductance and capucity.

In order to work out the expression (1) for these cases it is necessarv to know the value of the effective capacity of the secondary coil with greater accuracy than was required in the former cases. After several methods had been tried for the determination of this quantity, the following was finally 
adopted. The condenser having been disconnected from the primary circuit, a current was passed through the primary coil and the curve of secondary potential, produced at its interruption, was photographed. Under these circumstances the oscillations of the system depend only on the constants of the secondary circuit, and should give the value of the product of the self-inductance and capacity of the secondary coil. The photograph showed, in fact, a single damped oscillation with period" lengthening as the oscillations died away owing to the variation in the permeability of the core, The period was measured in the early part of the curve, where the amplitude is large, and was found to be $\cdot 001763$ sec. Taking this as being equal to $2 \pi \sqrt{\mathrm{L}_{2} \mathrm{C}_{2}}$, we have

$$
\mathrm{L}_{2} \mathrm{C}_{2}=0.787 .10^{-7} \text {. }
$$

A condenser, of small known capacity $\mathrm{C}_{2}{ }^{\prime}$, was then connected to the secondary coil and the period of this circuit, with the primary open, determined. This gives in the same way the value of $\mathrm{L}_{2}\left(\mathrm{C}_{2}+\mathrm{C}_{2}^{\prime}\right)$. From these two results the values of $\mathrm{L}_{2}$ and $\mathrm{C}_{2}$ can be determined. The values so found were $\mathrm{L}_{2}=2350$ henries, $\mathrm{C}_{2}=0000335$ microfarad. These values were used in working out the expression (1) for the following three cases. It may be noticed, however, that it is not so important to know the values of $\mathrm{L}_{2}$ and $\mathrm{C}_{2}$ separately as it is to know their product; $\mathrm{C}_{2}$ occurs separately only in the damping factors of the two oscillations represented by (1).

The self-inductance of the primary coil was determined by connecting to it the largest capacity available $(20 \cdot 73$ microfarads), and photographing the curve of secondary potential produced at the interruption of a current in the primary. The curve obtained shows a double oscillation; but, since $\mathrm{L}_{1} \mathrm{C}_{1}$ is much greater than $\mathrm{L}_{2} \mathrm{C}_{2}$, one of the oscillations has a much longer period than the other, and it is not difficult to determine the frequency of the slower oscillation from the photograph. On substituting in the expression (2) we obtain the value of $\mathrm{L}_{1}$.

As the potentials obtained in the following experiments were higher than those in the former cases, the oscillograph was made less sensitive by withdrawing the attracting plate to a greater distance from the steel strip. To prevent sparking inside the instrument the attracting plate was enclosed in a thicker sheath of ebonite. The distance of the edge of the plate from the strip was about $7 \mathrm{~mm}$. 
716 Prof. E. Taylor Jones and Mr. D. E. Roberts on

Case V.-The constants for this case were :

$$
\begin{aligned}
& \mathrm{L}_{1}=0 \cdot 1974 \text { henries. } \\
& \mathrm{L}_{2}=2350, ", \\
& \mathrm{C}_{1}=15.95 \text { microfarad. } \\
& \mathrm{C}_{2}=\cdot 0000335, " \\
& k^{2}=0 \cdot 8142 . \\
& \mathrm{M}=19 \cdot 44 \text { henries. } \\
& \mathrm{R}_{1}=1 \cdot 90 \text { ohms. } \\
& \mathrm{R}_{2}=38000, \\
& i_{0}=4 \cdot 3 \text { amperes. }
\end{aligned}
$$

The expression (2) gives for the frequencies

$$
n_{1}=88 \cdot 98, \quad n_{2}=1329 \cdot 3 \text {. }
$$

By (1) the secondary potential is

$$
\begin{aligned}
2 \mathrm{~V}_{2} & =46950 e^{-4 \cdot 654 t} \sin (32033 t-0 \cdot 05) \\
& -3143 e^{-62 \cdot 72 t} \sin (478548 t-0 \cdot 8) .
\end{aligned}
$$

The curve representing the square of this expression is shown in fig. 5 , and its maximum value is 48960 volts. The

Fig. 5.

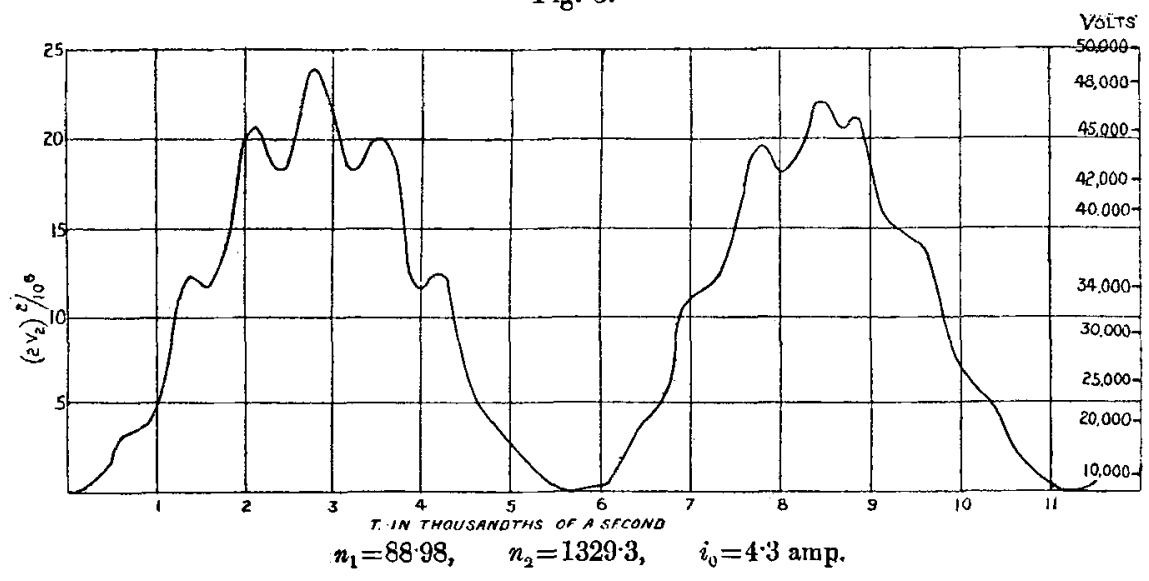

photograph is given in Plate XIII. fig. 12, but it should be stated that the amplitude of the short wave varied considerably in different photographs, it being sometimes larger, sometimes smaller than is here shown. As in some other cases, these variations appear to arise from irregularities in the action of the interrupter. 
The oscillograph was standardised in this and the two following cases, not directly with the air-core coil, but with the coil and condensers used in Case III., the greatest deflexion for a current of 8.5 amperes in that case being taken as representing 26500 volts. A comparison of the curves leads to 39480 volts as the greatest observed value of the secondary potential, which is again considerably below the calculated value.

The sparking-distance between the two spheres with the same primary current was found to be $1 \cdot 6$ centimetres.

Case VI.-In order to approximate more closely to the ordinary working conditions of an induction-coil, the primary capacity was now considerably reduced in value. This has the effect of increasing the secondary potential, and at this stage it was noticed that at high potentials a brush discharge took place freely between the ebonite sheath enclosing the attracting plate of the oscillograph and other parts of the instrument. The attracting plate and its connecting rod were therefore provided with still thicker coverings of ebonite, and the terminals of the instrument were removed to a greater distance from each other, in order to diminish as far as possible the leakage due to this cause.

The primary capacity was in the present case 3.89 microfarads, which gives, by (2), using the values given under Case V. for the other constants of the circuits,

$$
n_{1}=174 \cdot 4, \quad n_{2}=1371 .
$$

The expression for the secondary potential in volts is

$$
\begin{aligned}
2 \mathrm{~V}_{2} & =21650 i_{0} e^{-4 \cdot 14 t} \sin (62770 t-0 \cdot 1) \\
& -2753 i_{0} e^{-65 \cdot 26 t} \sin (493452 t-0 \cdot 83),
\end{aligned}
$$

where $i_{0}$ is the primary current in amperes. The curve representing the square of this expression was drawn for $i_{0}=2 \cdot 25$ amperes, and is shown in fig. 6 (p. 718).

Photographs were taken at the interruption of various currents in the primary circuit. One of these is shown in Plate XIII. fig. 13. The curves obtained were all of the same type, only the amplitude varying with the primary current. The greatest ordinate in each photographic curve was measured and compared with that of the standardising curve. The results are contained in Table I., in which the first column contains the values of the current interrupted in

Phil. Mag. S. 6. Vol. 22. No. 131. Nov. 1911. 3 B 
718 Prof. E. Taylor Jones and Mr. D. E. Roberts on

the primary circuit, the second the maximum potential calculated by (1), the third the maximum potential deduced by measurement of the plates.

Fig. 6.

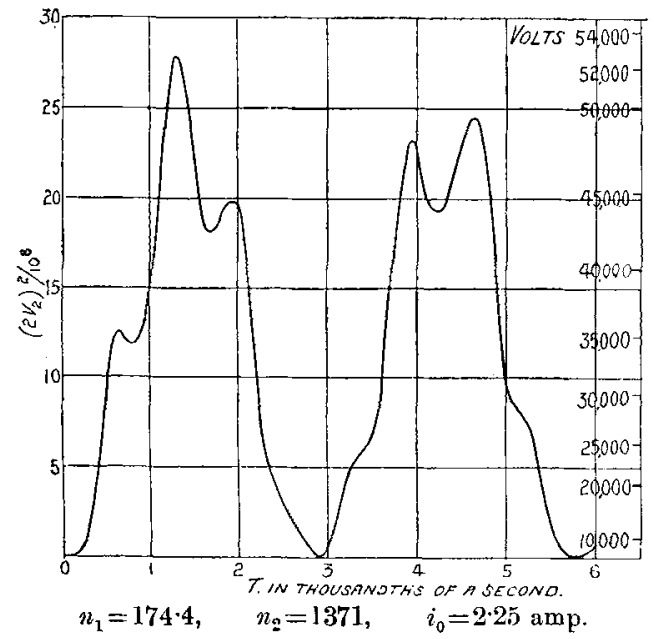

TABLE I.

\begin{tabular}{|c|c|c|}
\hline \multirow{2}{*}{$\begin{array}{c}i_{0}, \\
\text { amperes. }\end{array}$} & \multicolumn{2}{|c|}{ Maximum Potential in volts. } \\
\cline { 2 - 3 } & Calc. & Obs. \\
\hline $2 \cdot 64$ & 61910 & 72220 \\
$3 \cdot 16$ & 74110 & 84110 \\
$3 \cdot 90$ & 91460 & 101070 \\
$4 \cdot 44$ & 104120 & 118560 \\
$5 \cdot 10$ & 119600 & 132940 \\
\hline
\end{tabular}

The greatest spark-length observed between the two spheres with the current of $5 \cdot 1$ amperes, was $7 \cdot 3$ centimetres.

The observed value of the secondary potential is in this case greater than the calculated value. Probably the calculated value is too small, owing to the fact that the expression (1) does not correctly represent the phase relation of the two oscillations, as we see by comparing the photograph Pl. XIII. fig. 13, with the calculated curve fig. 6 . 
Case VII. The primary capacity was further reduced, its value in this case being 2.933 microfarads. Taking the other constants as before, we have

$$
n_{1}=198 \cdot 2, \quad n_{2}=1388,
$$

and the expression for the secondary voltage is

$$
\begin{gathered}
2 \mathrm{~V}_{2}=24730 i_{0} e^{-3 \cdot 975 t} \sin (71359 t-0 \cdot 12) \\
-3530 i_{0} e^{-65 \cdot 42 t} \sin (499860 t-0 \cdot 83) .
\end{gathered}
$$

The curve, calculated for $i_{0}=3 \cdot 4$ amperes, is shown in fig. 7 .

Fig. 7.

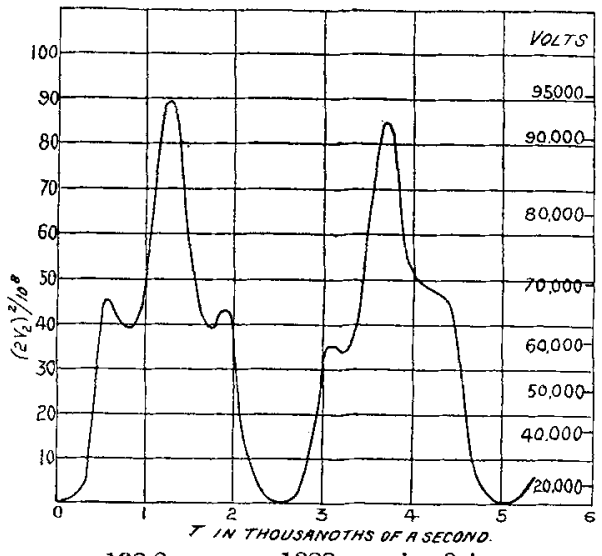

$$
n_{1}=198 \cdot 2, \quad n_{2}=1388, \quad i_{0}=3 \cdot 4 \text { amp. }
$$

'The photograph shown in Plate XIII. fig. 14 is typical of the oscillograph curves obtained in this case. It again differs from the calculated curve in the relative phases of the two oscillations, and this probably accounts in part for the differences between the observed and calculated maximum voltages given in Table II.

TABLE II.

\begin{tabular}{|c|c|c|}
\hline $\begin{array}{c}i_{0}, \\
\text { nmperes. }\end{array}$ & \multicolumn{2}{|c|}{ Maximum Potential in volts. } \\
\hline $2 \cdot 54$ & Calc. & Obs. \\
\hline $3 \cdot 24$ & 75630 & 70440 \\
$4 \cdot 00$ & 89430 & 76950 \\
$4 \cdot 42$ & 110400 & 101100 \\
$5 \cdot 10$ & 122000 & 112100 \\
\hline
\end{tabular}

3 B 2 
With the current $5 \cdot 1$ amperes the greatest sparking-distance between the two spheres was found to be $11 \cdot 2$ centimetres.

To sum up, the results given above show that the expression (1) represents in its main features the wave of potential at the terminals of the secondary coil when a current is interrupted in the primary, and that it also gives the order of magnitude of the maximum secondary potential. In each of the cases described above some uncertainty with regard to the maximum potential arises from the fact that the amplitude of the oscillograph curve is not always the same with the same primary current; and although each curve was photographed a number of times and the curve of greatest amplitude selected for measurement, we could never be quite certain that the greatest possible amplitude was actually obtained.

Similar differences are observed with other kinds of interrupter. In Plate XIII. fig. 15, are shown the curves of secondary potential at two successive interruptions of the primary current produced by a motor mercury-interrupter of the centrifugal type. The coils and condenser in action at the time were the same as in Case VII.

Bangor, July 1911.

LXIX. On the Spectra of the Electrodeless Ring Discharge in certain Gases. By H. Donaldson, B.A. (Camb.), B.Se. (Lond.), Scholar of Sidney Sussex College, Ciambridge*.

I $\mathrm{N}$ an ordinary discharge tube with electrodes, the inter1 pretation of the differences in the spectra of a gas in different parts of the tube is rendered difficult by the separation which takes place between the positive and negative ions.

It was thought, therefore, that a study of the spectra of gases in the oscillatory ring discharge, in which a permanent separation between the ions would be unlikely, might afford useful information concerning the dependence of the spectra upon the strength of the ionizing field.

\section{Apparatus.}

The bulbs in which the discharge was obtained were usually about $8 \mathrm{~cm}$. in diameter and were surrounded by a coil of half a dozen turns of well insulated wire wound closely so that the depth of the coil was about $2 \mathrm{~cm}$. The plane through the centre of the coil parallel to the windings was also a

* Communicated by Professor Sir J. J. Thomson. 
JONES \& ROBERTS.

Phil. Mag. Ser. 6, Vol. 22, Pl. XII.

FIG. 8.

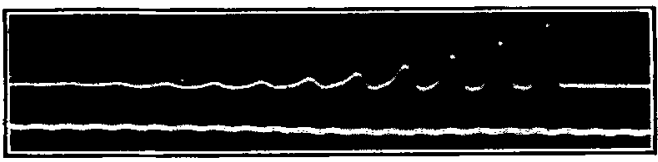

Case I.

$$
i_{0}=5.05 \text { amperes. }
$$

Fig. 9.

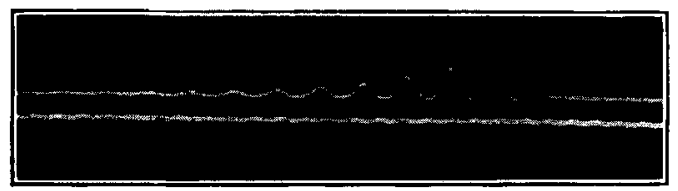

Case II.

$$
i_{0}=4.02 \text { amperes. }
$$

FIG. 10.

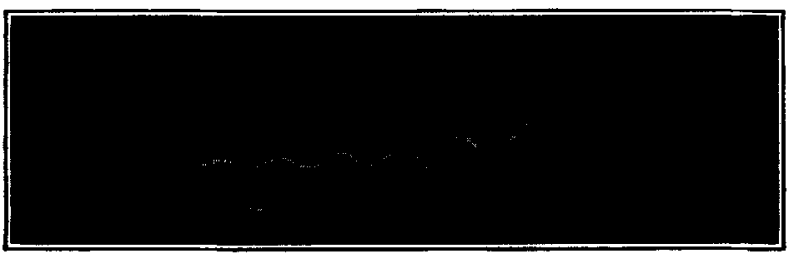

Case III.

$$
i_{0}=9 \cdot 1 \text { amperes }
$$

FIg. 11.

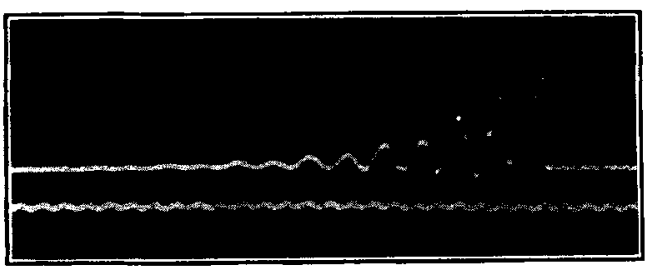

Case IV.

$i_{0}=5.8$ amperes. 
Fig. 12.

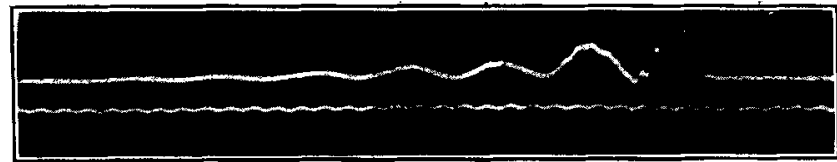

Case V. $i_{0}=+\cdot 3$ amperes.

FIg. 13.

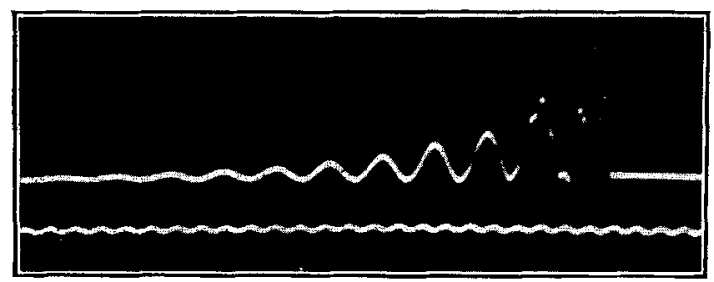

Case VI.

$$
i_{0}=4 \cdot 44 \text { amperes. }
$$

Fig. 14.

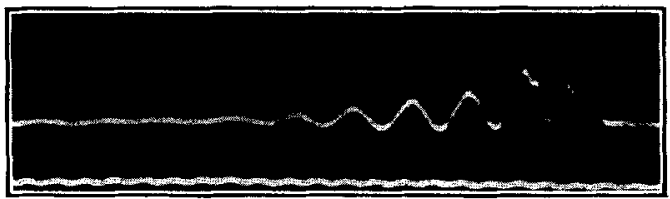

Case VII.

$$
\imath_{\mathrm{o}}=2 \cdot 4 \text { amperes. }
$$

Fig. 15.

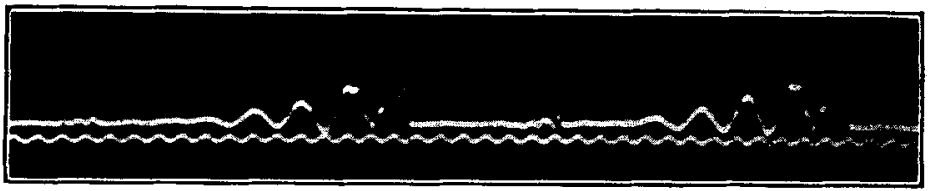

Case VII with motor interrupter. 